\begin{tabular}{|c|c|}
\hline \multirow{3}{*}{ 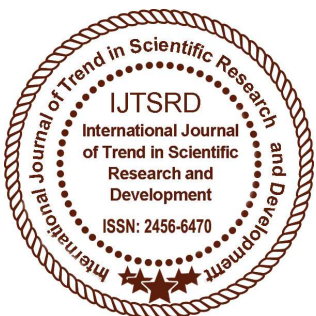 } & $\begin{array}{l}\text { International Journal of Trend in Scientific } \\
\text { Research and Development (IJTSRD) }\end{array}$ \\
\hline & International Open Access Journal \\
\hline & ISSN No: 2456 - 6470 | www.ijtsrd.com | Volume - 1 | Issue - 6 \\
\hline
\end{tabular}

\title{
Hydromagnetic Flow of Nanofluids over a Nonlinear Shrinking Surface with Heat Flux and Mass Flux
}

\author{
Mekala Selvaraj \\ Department of Mathematics, Bharathiar University, \\ Coimbatore-46, Tamil Nadu, India
}

\author{
S. P. Anjali Devi \\ Department of Applied Mathematics, Bharathiar \\ University, Coimbatore-46, Tamil Nadu, India
}

\section{ABSTRACT}

Heat and mass transfer characteristics of water based nanofluids over a nonlinear shrinking surface with suction is studied numerically in the incidence of magnetic field, thermal radiation under the boundary conditions heat flux and mass flux. Similarity transformations are used to renovate the governing partial differential equations into higher order nonlinear ordinary differential equations. These equations are numerically solved using fourth order RungeKutta technique along with Nachistem Swigert shooting method. Numerical results are achieved for the nanofluid velocity, nanofluid temperature and nanoparticle concentration as well as for the skin friction coefficient, wall temperature and concentration of the wall for various values of governing physical parameters viz. magnetic interaction parameter, suction parameter, shrinking parameter, thermal radiation parameter, temperature ratio parameter and solid volume fraction of the nanoparticles such as copper and silver.

Keywords: Nanofluid, MHD, Radiation, Shrinking sheet, heat flux, mass flux

\section{INTRODUCTION}

Research of boundary layer flow over a shrinking sheet has very much interest on last few years due to its vast range of practical applications in industries. Shrinking sheet is a surface which decreases in size to a certain area due to an imposed suction or external heat. One of the most common applications of shrinking sheet problems in industries is shrinking flim. Shrinking flim phenomenon is very supportive in packaging bulk products as it can be unwrapped easily with adequate heat. The viscous boundary layer flow over a shrinking sheet was first coined by wang (1990)[1]. In this work, he concluded that the boundary layer flow over a shrinking surface have suction effect on the boundary. Following this pioneering work, many researchers have been investigated on the research area of shrinking sheet. Some of the researchers are Miklav et.al (2006) [2], wang (2008) [3], Fang (2009) [4], Arifin et.al (2011) [5], Rohniet.al(2012) [6], Bachok et. al (2012) [7], AnuarIshak et. al (2013) [8], Kalidas Das (2014) [9] and Rahman et al.(2016) [10].

Magneto hydrodynamics (MHD) has many engineering applications in the real world such as astrophysics(planetary magnetic field), MHD pumps, MHD generators, MHD flow meters, jet printers, fusion reactors and so on. As a result of the wide applications of MHD, MHD boundary layer flow of viscous fluid over a stretching sheet was studied by numerous researchers. Andersson et al.(1992) [11] studied the effect of hydromagnetic flow of a power law fluid over a stretching sheet. Hydromagnetic boundary layer flow of a viscous incompressible fluid which is caused by a sheet stretching according to a power law velocity distribution in the presence of a magnetic field was investigated by Chaim (1995) [12]. Thermal radiation effects on an electrically conduction fluid arise in many physical or practical applications such as electrical power generation, solar 
power technology, nuclear reactors and nuclear water disposed. Radiation effects on boundary layer flow with or without considering the magnetic field have been researched by several authors under certain contions. The hydromagnetic flow fast a flat plate by the presence of radiation was analysed by Raptis and Massallas (1998) [13].The problem of radiation effects on the heat transfer over a stretching surface has been solved by Elbashbeshy (2000) [14]. Heat transfer analysis for fluid flow over an exponentially stretching porous sheet with surface heat flux in porous medium was worked by Iswar Chandra Mandal (2013) [15]. Maiti (2014) [16] was published the effect of radiative heat flux of a magneto hydrodynamics micropolar fluid flow towards a stretching or shrinking vertical surface in presence of a heat source or sink. Stagination point flow of an electrically conducting micropolar fluid with MHD and radiation towads a horizontal shrinking sheet was published by Das and Sarkar (2016) [17].

A word nanofluid was first defined by Choi (1995) [18]. Nanofluid is a new domain of heat transfer fluids containing nanometer sized $(1-100 \mathrm{~nm})$ particles that are stable suspended in the conventional fluids like water, oil, ethylene glycol. Commonly used nanoparticles are oxide ceramics $\left(\mathrm{Al}_{2} \mathrm{O}_{3}, \mathrm{CuO}\right)$, metals $(\mathrm{Cu}, \mathrm{Ag}, \mathrm{Au})$, Semi conductors $\left(\left(\mathrm{TiO}_{2}, \mathrm{SiC}\right)\right.$, nitride ceramics(AlN,SiN) and etc. Due to nanofluids novel properties, it can be widely used for various heat transfer applications such as solar energy will maximized with the change of nanoparticle size,shape, volume fraction of nanoparticles, automotive and air conditioning cooling, cooling of transfer oil, improving diesel generator efficieny in nuclear reactor, defense and space. The research about nanofluid was reported by several researchers [YiminXuan (2000) [19], Das et. al(2003) [20],Phelan et. al (2005) [21],Ding et. al (2007) [22], Manca(2010) [23]]. The unsteady stagination point flow over a shrinking/stretching sheet with heat transfer in the presence of prescribed heat flux was researched by Sualiet. al (2012) [24]. Winifred NdukuMutuku (2014) [25] published the effects of MHD nonlinear boundary layer flow and heat transfer of nanofluids past a permeable moving flat surface with thermal radiation and viscous dissipation. The problem of MHD boundary layer flow of copper water nanofluid and alumina water nanofluid over a moving permeable flat plate has been solved by Eshetuhaile and Shankar (2015) [26]. SandeepNaramgar and Sulochana (2016) [27] investigated about the nanofluid flow past a stretching and shrinking sheet under the consideration of magnetic field with suction/injection.

Hence there is no work has been researched on steady, two dimensional flow of nanofluids over a nonlinear shrinking sheet with nonlinear thermal radiation and MHD in the presence of heat flux and mass flux. This study focused on nanofluids is the water based metal nanoparticles such as $\mathrm{Cu}$ and $\mathrm{Ag}$.

\section{MATHEMATICAL FORMULATIONS}

\section{A. Governing Equations}

The problem of steady, hydromagnetic incompressible, viscous, two dimensional boundary layer flow of a nanofluid over a nonlinear shrinking sheet with prescribed heat flux and mass flux is considered. The $\mathrm{x}$ - axis chosen in the direction of the flow along the nonlinear shrinking surface and y- axis is chosen normal to the shrinking surface with velocity components $\mathrm{u}=\mathrm{u}_{\mathrm{w}}(\mathrm{x})=\mathrm{cx}^{\mathrm{n}}, \mathrm{c}>0$ and $\mathrm{v}$ in these directions. The nonlinear shrinking surface is subjected to suction. Two types of water based nanofluids are considered for this work. The Schematic diagram of the problem is given in Fig. (1).

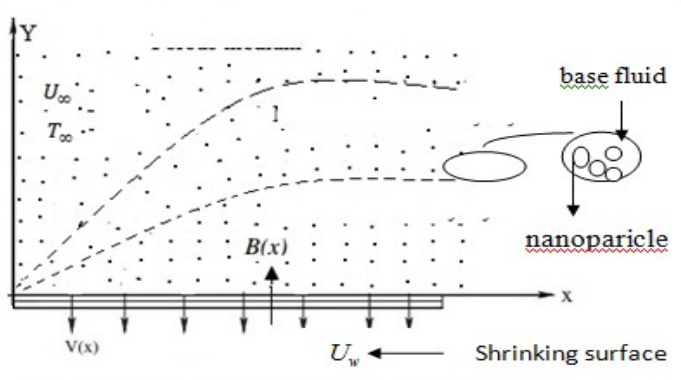

Fig.(1) Schematic diagram of the problem

Assume that the non uniform transverse magnetic field of $\operatorname{strength}^{B}(x)=B_{0} x^{\frac{n-1}{2}}\left(\right.$ Chaim (1995))), $\mathrm{B}_{0}$ is the uniform magnetic field is applied in the $\mathrm{y}$ direction. It is also assumed that the ambient temperature is constant, denoted by $T_{\infty}$ and $T_{w}=T_{\infty}+b x^{m}$ is the surface temperature with $m$ being surface temperature parameter and $b$ is a positive constant. Consider the nanofluids to be gray, absorbing and emitting radiation but non scattering medium. Also the radiative heat flux $\mathrm{q}_{\mathrm{r}}$ is negligible in $\mathrm{x}$ axis when compared to that in the $\mathrm{y}$ direction in the energy equation is described using Rosseland approximation. 
Hence, under the above consideration and boundary layer assumptions, the governing equations of the hydromagnetic flow of nanofluid over a nonlinear shrinking surface is given by

$$
\begin{aligned}
& \frac{\partial u}{\partial x}+\frac{\partial v}{\partial y}=0 \\
& u \frac{\partial u}{\partial x}+v \frac{\partial u}{\partial y}=\frac{\mu_{n f}}{\rho_{n f}} \frac{\partial^{2} u}{\partial y^{2}}-\frac{\sigma B(x)^{2}}{\rho_{n f}} u \\
& u \frac{\partial T}{\partial x}+v \frac{\partial T}{\partial y}=\alpha_{n f} \frac{\partial^{2} T}{\partial y^{2}}-\frac{1}{\left(\rho c_{p}\right)_{n f}} \frac{\partial q_{r}}{\partial y} \\
& u \frac{\partial C}{\partial x}+v \frac{\partial C}{\partial y}=D \frac{\partial^{2} C}{\partial y^{2}}
\end{aligned}
$$

where $\mathrm{u}$ and $\mathrm{v}$ are the velocity components of the $\mathrm{x}$ and $\mathrm{y}$ axes respectively, $\sigma$ is the electrical conductivity, $\mu_{n f}$ is the effective dynamic viscosity of the nanofluid, $\rho_{\mathrm{nf}}$ is the density of the nanofluid, $\alpha_{\mathrm{nf}}$ is the thermal diffusivity of the nanofluid, $c_{p}$ is the specific heat at constant pressure, $\mathrm{D}$ is the thermodiffusion coefficient. Using Rosseland approximation, the net radiative heat flux is written as,

$$
\begin{gathered}
q_{r}=-\frac{16 \sigma^{*}}{3 k^{*}}\left(T^{3} \frac{\partial T}{\partial y}\right) \\
\frac{\partial}{\partial y}\left(q_{r}\right)=-\frac{16 \sigma^{*}}{3 k^{*}}\left(3 T^{2}\left(\frac{\partial T}{\partial y}\right)^{2}+T^{3} \frac{\partial^{2} T}{\partial y^{2}}\right)(5)
\end{gathered}
$$

Where $\sigma^{*}$ is the Stefan-Boltzmann constant and $\mathrm{k}^{*}$ is the mean absorption coefficient.

\section{B. Thermophysical properties of the Nanofluid}

The present study, water is considered as the base fluid with Prandtl number $\operatorname{Pr}=6.2$. The nanofluids are the mixer of water with solid spherical copper and silver nanoparticles.

The viscosity, specific heat capacity, density, thermal diffusivity and thermal conductivity of the nanofluids depend on the volume fraction $\varphi$ of the nanoparticles used.

The thermal diffusivity of the nanofluid is given by

$$
\alpha_{n f}=\frac{k_{n f}}{\left(\rho c_{p}\right)_{n f}}
$$

Where $k_{n f}$ and $\left(\rho c_{p}\right)_{n f}$ are the thermal conductivity of the nanofluid and specific heat capacity of the nanofluid
Following the lines of Hady et al. (2012) [28] the effective density, specific heat capacity, dynamic viscosity \& thermal conductivity of the nanofluid are given by

$\rho_{n f}=(1-\phi) \rho_{f}+\phi \rho_{s}$

$\left(\rho c_{p}\right)_{n f}=(1-\phi)\left(\rho c_{p}\right)_{f}+\phi\left(\rho c_{p}\right)$

$\mu_{n f}=\frac{\mu_{f}}{(1-\phi)^{2.5}}, \quad k_{n f}=k_{f} \frac{\left(k_{s}+2 k_{f}\right)-2 \phi\left(k_{f}-k_{s}\right)}{\left(k_{s}+2 k_{f}\right)+\phi\left(k_{f}-k_{s}\right)}$

Where, $\rho_{n f}$ is the density of the nanofluid, $\mu_{n f}$ is the effective viscosity of the nanofluid, $v_{n f}$ is the kinematic viscosity of the nanofluid, $\varphi$ is the solid volume fraction, $\mathrm{c}_{p}$ is the specific heat at constant pressure, $\rho_{f}$ and $\rho_{s}$ are the densities of the base fluid and the nanoparticle. $\left(\rho c_{p}\right)_{f}$ and $\left(\rho c_{p}\right)_{s}$ are the specific heat capacities of the base fluid and the nanoparticles respectively and $k_{f}$ and $k_{s}$ are the thermal conductivities of the base fluid and the nanoparticles respectively. The relation for effective dynamic viscosity $\mu_{n f}$ used in the present study is taken from the equation by Brinkman (1952). The Thermophysical properties of water and nanoparticles are tabulated in Table 1.

Table 1: Thermo-Physical Properties Of Fluid And Nanoparticlesat $25^{\circ} \mathrm{C}$

\begin{tabular}{|c|c|c|c|}
\hline $\begin{array}{c}\text { Physical } \\
\text { properties }\end{array}$ & $\begin{array}{c}\text { Water } \\
\text { fluid }\end{array}$ & Cu & Ag \\
\hline $\mathbf{C}_{\mathbf{P}}$ & 4179 & 385 & 235 \\
\hline$\rho$ & 997.1 & 8933 & 10500 \\
\hline $\mathbf{K}$ & 0.613 & 400 & 429 \\
\hline$\alpha$ & 1.47 & 1163.1 & 1738.6 \\
\hline
\end{tabular}

\section{Boundary conditions}

The boundary conditions of the prescribed heat flux and mass flux of the problem is defined as follows, $-k_{n f} \frac{\partial T}{\partial y}=q_{w} \quad$ And $\quad-D \frac{\partial C}{\partial y}=m_{w}$, here surface heat flux $q_{w}$ and surface mass flux $\mathrm{m}_{\mathrm{w}}$.

Therefore, the appropriate boundary conditions are, $u=-U_{w}(x), v=-V_{w}(x),-k_{n f} \frac{\partial T}{\partial y}=q_{w},-D \frac{\partial C}{\partial y}=m_{w}$

at $\mathrm{y}=0$

$u \rightarrow 0, T \rightarrow T_{\infty}, \mathrm{C} \rightarrow \mathrm{C}_{\infty}$ as $\quad y \rightarrow \infty$ 
$V_{w}(x)$ is the variable suction velocity. The non dimensional parameters appeared in

$V_{w}(x)=\sqrt{\frac{C(n+1) v_{f}}{2}} x^{\frac{n-1}{2}}$

equations (11) to (14) are defined as follows $M^{2}=\frac{2 \sigma B_{0}^{2}}{c(n+1) \rho_{f}}$ is the magnetic interaction

\section{Similarity transformations}

To assist the analysis, the following similarity transformations are introduced.

$$
\begin{aligned}
& \psi=\sqrt{\frac{2 c v}{(n+1)}} x^{\frac{n+1}{2}} f(\eta) \\
& \eta=y \sqrt{\frac{c(n+1)}{2 v}} x^{\frac{n-1}{2}}, \\
& T-T_{\infty}=\frac{q_{w}}{k_{n f}} \sqrt{\frac{2 v_{f}}{c(n+1)}} x^{\frac{1-n}{2}} \theta(\eta) \\
& C-C_{\infty}=\frac{m_{w}}{D} \sqrt{\frac{2 v_{f}}{c(n+1)}} x^{\frac{1-n}{2}} \phi(\eta)(9)
\end{aligned}
$$

The horizontal and vertical velocity components are derived by using stream functions

$$
\begin{aligned}
& u=\frac{\partial \psi}{\partial y}=c x^{n} f^{\prime}(\eta) \text { and } \\
& v=-\frac{\partial \psi}{\partial x}=-\sqrt{\frac{c(n+1) v_{f}}{2}} x^{\frac{n-1}{2}}\left[f(\eta)+\frac{n-1}{n+1} \eta f^{\prime}(\eta)\right](10)
\end{aligned}
$$

The continuity equation is satisfied identically. Therefore, the transformed momentum equation, energy equation and concentration equation is known by

$$
\begin{gathered}
f^{\prime \prime \prime}+(1-\phi)^{2.5}\left(\phi_{1}\left(f f^{\prime \prime}-\beta\left(f^{\prime}\right)^{2}\right)-M^{2} f^{\prime}\right)=0 \\
\theta^{\prime \prime}\left(1+\frac{4}{3 N_{R}} \frac{k_{f}}{k_{n f}}\left\{1+\left(\theta_{w}-1\right) \theta\right\}^{3}\right)+\frac{4}{N_{R}} \frac{k_{f}}{k_{n f}}\left(1+\left(\theta_{w}-1\right) \theta\right)^{2}\left(\theta_{w}-1\right) \theta^{\prime 2} \\
+\operatorname{Pr} \frac{k_{f}}{k_{n f}}\left(\phi_{2}\left(f \theta^{\prime}-2 \beta f^{\prime} \theta\right)\right)=0
\end{gathered}
$$

$\phi^{\prime \prime}+S c f \phi^{\prime}=0$

Where $\phi_{1}=1-\phi+\phi\left(\frac{\rho_{s}}{\rho_{f}}\right), \quad \phi_{2}=1-\phi+\phi \frac{\left(\rho c_{p}\right)_{s}}{\left(\rho c_{p}\right)_{f}}$

with the corresponding boundary conditions obtain from equation (5) in the following form

$$
\begin{aligned}
& f(0)=f_{w}, f^{\prime}(0)=-1, \theta^{\prime}(0)=-1, \phi^{\prime}(0)=-1 \\
& \eta=0, \\
& f^{\prime}(\infty)=0, \theta(\infty) \rightarrow 0 \phi(\infty) \rightarrow 0 \quad \text { as } \quad \eta \rightarrow \infty
\end{aligned}
$$

parameter, $N_{R}=\frac{k_{f} k^{*}}{4 \sigma^{*} T_{\infty}^{3}}$ is the radiation parameter $\operatorname{Pr}=\frac{v_{f}\left(\rho c_{p}\right)_{f}}{k_{f}}$ is the Prandtl number,$_{\theta_{w}}=\frac{T_{w}}{T_{\infty}}$ is the temperature ratio parameter, $\beta=\frac{2 n}{n+1}$ is the shrinking parameter, $\mathrm{f}_{\mathrm{w}}$ is the suction parameter, $S c=\frac{v_{,}}{D}$ is the Schmidt number.

\section{E. Physical quantities of interest}

The quantities of engineering interest in this study are the non-dimensional skin friction coefficient

$$
\begin{aligned}
& C_{f}= \frac{\tau_{w}}{\rho_{f} u_{w}^{2}} \text { where } \tau_{w}=\mu_{n f}\left(\frac{\partial u}{\partial y}\right)_{y=0} \text { (15) } \\
& C_{f}\left(\operatorname{Re}_{x}\right)^{1 / 2}=\frac{\sqrt{n+1}}{(1-\phi)^{2.5}} f^{\prime \prime}(0), \quad \text { where } \operatorname{R~}_{x}=\frac{c x^{n+1}}{v} \text { is the }
\end{aligned}
$$

Reynolds number

\section{NUMERICAL SOLUTIONS}

The set of nonlinear coupled ordinary differential equations (11) to (13) subject to the boundary conditions in (14) constitute a nonlinear boundary value problem which is reduced to an initial value problem to start with. In order to solve these numerically, the most efficient numerical shooting technique such as the Nachtshiem-Swigert iteration shooting scheme is utilized to satisfy the asymptotic boundary conditions at $\eta \rightarrow \infty$. The appropriate finite values of $\eta \rightarrow \infty$ are chosen. Some initial conditions are required to solve the above equations. Hence three initial conditions $f^{\prime \prime}(0), \theta(0), \phi(0)$ which are not prescribed are to be obtained using NachtshiemSwigert shooting iteration technique. Now the boundary value problem is converted into initial value problem and has been solved numerically using fourth order Runge-Kutta integration method. The crux of the problem lies in making good guesses for $f^{\prime \prime}(0)$, $\theta(0), \phi(0)$. They are guessed properly to get the convergence and solution for various values of physical parameters. The accuracy level is chosen up to $10^{-5}$.

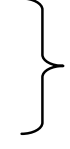




\section{RESULTS AND DISCUSSIONS}

The accuracy of the present method was authorized by comparisons with numerical values of local Nusselt number by previously published articles Ishak et al.(2008) [29] and Elsayed et al.(2010)[30] in the absence of volume fraction, without taking of radiation and the value of temperature ratio parameter is 1.0 and the shrinking parameter is $1 / 2$. The numerical results are in Table 2. From this table, our results are good concurrence with the authors' results Ishak et al. and Elsayed et al. for different values of Prandtl

\begin{tabular}{|l|l|l|l|}
\hline Pr & $\begin{array}{l}\text { Ishak et } \\
\text { al.[29] }\end{array}$ & $\begin{array}{l}\text { Elsayed et } \\
\text { al.[30] }\end{array}$ & $\begin{array}{l}\text { Present } \\
\text { results }\end{array}$ \\
\hline 0.72 & 0.8086 & 0.808 & 0.80863 \\
1.0 & 1.0 & 1.0 & 1.0 \\
10.0 & 3.7202 & 3.7207 & 3.72067 \\
\hline
\end{tabular}

number

TABLE 2: COMPARISON OF LOCAL NUSSELT NUMBER AT $\phi=0.0, N_{R} \rightarrow \infty, \theta_{W}=1.0$ AND $\beta=\frac{1}{2}$ AT DIFFERENT VALUES OF PR
WITHPREVIOUSLY RESEARCHED DATA

The numerical solution of the problem is found and the effects of the physical parameters on the flow, temperature and concentration are depicted through graphs. Also the engineering interest of physical quantities such as skin friction coefficient, wall temperature and concentration of the wall is given in tabular form.

In this problem, the nanoparticles solid volume fraction is fixed in the range of $0 \leq \phi \leq 0.2$, magnetic interaction parameter $\mathrm{M}^{2}=0.5,1.0,2.0,2.5$,shrinking parameter $\beta=-1.0,1.0,1.5,2.0$, suction parameter $\mathrm{f}_{\mathrm{w}}$ $=2.0,2.3,2.4,2.5$, The radiation parameter $\mathrm{N}_{\mathrm{R}}=1.0$, $1.5,2.0,2.5$, The temperature ratio parameter $\theta_{\mathrm{w}}=$ $0.8,0.9,1.1,1.2$ and Schmidt number $\mathrm{Sc}=0.3,0.5$, $0.7,0.8$ are obtained and demonstrated by means of graphs.

The effect of magnetic field on velocity, temperature and concentration of nanofluids for both copper water nanofluid and silver water nanofluid is shown in figs. 2, 3 and 4. It is noted that in the shrinking surface the nanofluid velocity increased for increasing magnetic parameter. From fig. 3 and fig.4 the nanofluids temperature and concentration decreases due to the effect of magnetic field. But the thermal boundary layer thickness has very small amount of variation while increasing the values of magnetic interaction parameter.

The impact of shrinking parameter over dimensionless velocity is portrayed in fig.5. The figure proves that the nonlinear shrinking parameter shrinks the velocity of both copper water nanofluid and silver water nanofluid. Fig.6 illustrates the dimensionless temperature distribution for various values of shrinking parameter. For increased values of shrinking parameter, the nanofluid temperature lifts and the thermal boundary layer thickness increased. The effects of shrinking parameter on nanoparticle concentration are displayed in fig.7. For both nanofluids, the shrinking parameter rises the nanoparticle concentration when $\phi=0.05$.

Fig. 8 highlights the effects of suction parameter on the dimensionless velocity distribution. In the shrinking surface the values of suction parameter augments the nanofluid velocity for both nanofluids. Variation in dimensionless temperature and concentration distribution is visualized through figs. 9 and 10 . For enhances the values of suction parameter $\left(f_{w}>0\right)$, the thermal boundary layer thickness and concentration of both copper water nanofluid and silver water nanofluid gets decelerated.

Figs. 11, 12 and 13 elucidates the impact of solid volume fraction over the dimensionless velocity, temperature and concentration of copper water nanofluid and silver water nanofluid. The nanofluid velocity enlarges due to the variation in solid volume fraction is shown in fig.11. The thermal boundary layer thickness expands when the solid volume fraction enhance. In fig.13 The nanofluid concentration moves down to the boundary for increasing values of $\phi$.

Fig. 14 displays the effects of thermal radiation parameter on dimensionless temperature distribution. It is evident that the temperature of both nanofluids diminished due to radiation for both nanofluids. The effect of temperature ratio parameter on temperature distribution is illustrated in fig.15. It is seen that the temperature ratio parameter enrich the thermal boundary layer thickness for its increasing values.

Various values of Schmidt number on concentration is portrayed in fig.16. When we increase the values of 
Sc, the nanoparticle concentration decreases when solid volume fraction $\phi=0.05$.

Tables 3, 4 and 5 display the effect of various governing physical parameters of the problem on the skin friction coefficient, wall concentration and temperature of the wall. Table 3 presents the skin friction coefficient for different values of magnetic interaction parameter, suction parameter, shrinking parameter and solid volume fraction. The skin friction coefficient enhances due to the effect of magnetic field, suction and solid volume fraction.

The numerical values of wall concentration are given in table 4. It is observed that the shrinking parameter enhances the concentration of the wall. In the mean while magnetic interaction parameter, solid volume fraction, suction parameter and Schmidt number diminishes the concentration of the wall.

From table 5, it is inferred that the effect of magnetic field, suction and thermal radiation over the wall temperature is to suppress it while shrinking parameter, solid volume fraction and temperature ratio parameter enlarge the values of temperature of the wall.

\section{CONCLUSIONS}

The numerical solution of a two dimensional, laminar, nonlinear, steady boundary layer flow of a nanofluid over an incompressible steady shrinking surface subjected to prescribed heat and mass flux in the presence of thermal radiation and magnetic field with suction is obtained for various values of governing physical parameters in this investigation.

The numerical results predict the effects of different physical parameters such as magnetic interaction parameter, shrinking parameter, suction parameter, solid volume fraction, radiation parameter, temperature ratio parameter and Schmidt number.

The main results of the work can be summarized as follows:

\section{The momentum boundary layer thickness} enhanced due to the effect of magnetic interaction parameter, suction parameter and solid volume fraction. Consequently the shrinking parameter diminished the nanofluid velocity for both copper water nanofluid and silver water nanofluid.

$>$ The temperature distribution in the boundary layer flow region is enriched by the effect of shrinking parameter, solid volume fraction and temperature ratio parameter while opposite trend is occurred in temperature distribution for various values of magnetic interaction parameter, suction parameter and thermal radiation parameter.

An increase in magnetic interaction parameter, suction parameter, solid volume fraction and Schmidt number is to decrease the concentration distribution. But the shrinking parameter raises the nanofluids concentration.

$>$ The important physical quantity such as skin friction coefficient of the problem increased with increases the values of magnetic interaction parameter, suction parameter and solid volume fraction.

$>$ The temperature at the wall diminishes when we increase the physical parameters such as magnetic interaction parameter, suction parameter and thermal radiation parameter. Whereas the wall temperature boosts for increasing the shrinking parameter, solid volume fraction and temperature ratio parameter.

An increment in magnetic field, suction parameter, solid volume fraction and Schmidt number reduces the concentration of the wall while it increases with rises the values of shrinking parameter.

Ag water nanofluid has highest skin friction coefficient as compared to cu water nanofluid.

The numerical values of wall temperature and concentration of the wall of copper water nanofluid is superior to silver water nanofluid.

\section{TABLE 3: VARIATIONS IN SKIN FRICTION COEFFICIENT FOR VARIOUS VALUES OF $M^{2}, \beta, \phi$, AND $F_{W}$ WHEN $N=3.0$}

\begin{tabular}{|c|c|c|c|c|c|}
\hline $\mathbf{M}^{2}$ & $\beta$ & $\phi$ & $\mathrm{f}_{\mathrm{w}}$ & $\mathrm{Cu}-$ Water & $\mathrm{Ag}-$ Water \\
\cline { 5 - 6 } & & & & $C_{f}\left(\mathrm{Re}_{x}\right)^{1 / 2}$ & $C_{f}\left(\mathrm{Re}_{x}\right)^{1 / 2}$ \\
\hline 0.5 & 1.5 & 0.05 & 2.5 & 4.28818 & 4.55550 \\
1.0 & & & & 4.57177 & 4.82298 \\
1.5 & & & & 4.82269 & 5.06254 \\
2.0 & & & & 5.05009 & 5.28137 \\
\hline 2.0 & \multirow{2}{*}{1.5} & 0.0 & 2.5 & 3.90989 & 3.90989 \\
& & 0.05 & & 5.05009 & 5.28137 \\
& & 0.1 & & 6.24356 & 6.73162 \\
& & 0.2 & & 8.66328 & 9.68743 \\
\hline 2.0 & \multirow{2}{*}{1.5} & 0.05 & 2.0 & 4.08432 & 4.24979 \\
& & & 2.2 & 4.46966 & 4.66195 \\
& & & 2.3 & 4.66285 & 4.86827 \\
& & & 2.5 & 5.05009 & 5.28137 \\
\hline
\end{tabular}


TABLE 4: CONCENTRATION OF THE WALL $\phi(0)$ FOR VARIOUS VALUES OF $\mathbf{M}^{2}, \beta, \phi, \mathrm{F}_{\mathrm{W}}$ AND SC

\begin{tabular}{|c|c|c|c|c|c|c|}
\hline \multirow[t]{2}{*}{$\mathbf{M}^{2}$} & \multirow[t]{2}{*}{$\beta$} & \multirow[t]{2}{*}{$\phi$} & \multirow[t]{2}{*}{$\mathbf{f}_{\mathrm{w}}$} & \multirow[t]{2}{*}{ Sc } & $\mathrm{Cu}$ - Water & Ag - Water \\
\hline & & & & & $\phi(0)$ & $\phi(0)$ \\
\hline 0.5 & \multirow[t]{4}{*}{1.5} & \multirow[t]{4}{*}{0.05} & \multirow[t]{4}{*}{2.5} & \multirow[t]{4}{*}{0.5} & 0.89231 & 0.88786 \\
\hline 1.0 & & & & & 0.88770 & 0.88390 \\
\hline 1.5 & & & & & 0.88398 & 0.88065 \\
\hline 2.0 & & & & & 0.88088 & 0.87789 \\
\hline \multirow[t]{4}{*}{2.0} & 1.5 & \multirow[t]{4}{*}{0.05} & \multirow[t]{4}{*}{2.5} & \multirow[t]{4}{*}{0.5} & 0.88088 & 0.87789 \\
\hline & 2.0 & & & & 0.88128 & 0.87910 \\
\hline & 2.5 & & & & 0.88358 & 0.88041 \\
\hline & 3.0 & & & & 0.88512 & 0.88184 \\
\hline \multirow[t]{4}{*}{2.0} & \multirow[t]{4}{*}{1.5} & 0.0 & \multirow[t]{4}{*}{2.5} & \multirow[t]{4}{*}{0.5} & 0.89001 & 0.89001 \\
\hline & & 0.05 & & & 0.88088 & 0.87789 \\
\hline & & 0.1 & & & 0.87578 & 0.87109 \\
\hline & & 0.2 & & & 0.87365 & 0.85836 \\
\hline \multirow[t]{4}{*}{2.0} & \multirow[t]{4}{*}{1.5} & \multirow[t]{4}{*}{0.05} & 2.0 & \multirow[t]{4}{*}{0.6} & 1.16205 & 1.15627 \\
\hline & & & 2.2 & & 1.02963 & 1.02524 \\
\hline & & & 2.3 & & 0.97450 & 0.97066 \\
\hline & & & 2.5 & & 0.88088 & 0.87789 \\
\hline \multirow[t]{4}{*}{2.0} & \multirow[t]{4}{*}{1.5} & \multirow[t]{4}{*}{0.05} & \multirow[t]{4}{*}{2.5} & 0.5 & 0.88088 & 0.87789 \\
\hline & & & & 0.6 & 0.73106 & 0.72879 \\
\hline & & & & 0.7 & 0.62389 & 0.62213 \\
\hline & & & & 0.8 & 0.54364 & 0.54224 \\
\hline
\end{tabular}

TABLE 5: WALL TEMPERATURE $\Theta(0)$ FOR VARIOUS VALUES OF $\mathbf{M}^{2}, \beta, \phi, \theta_{W}, N_{R}$ AND $F_{W}$ WHEN Pr $=6.2$

\begin{tabular}{|c|c|c|c|c|c|c|c|}
\hline \multirow[t]{2}{*}{$\mathbf{M}^{2}$} & \multirow[t]{2}{*}{$\beta$} & \multirow[t]{2}{*}{$\phi$} & \multirow[t]{2}{*}{$\mathbf{f}_{\mathrm{w}}$} & \multirow[t]{2}{*}{$\mathbf{N}_{\mathrm{R}}$} & \multirow[t]{2}{*}{$\theta_{\mathrm{w}}$} & $\mathbf{C u}$ - Water & Ag - Water \\
\hline & & & & & & $\theta(0)$ & $\theta(0)$ \\
\hline $\begin{array}{l}0.5 \\
1.0 \\
1.5 \\
2.0\end{array}$ & 1.5 & 0.05 & 2.5 & 2.0 & 1.1 & $\begin{array}{l}0.15458 \\
0.15383 \\
0.15321 \\
0.15268\end{array}$ & $\begin{array}{l}0.15604 \\
0.15536 \\
0.15478 \\
0.15428\end{array}$ \\
\hline 2.0 & $\begin{array}{l}1.5 \\
2.0 \\
2.5 \\
3.0\end{array}$ & 0.05 & 2.5 & 2.0 & 1.1 & $\begin{array}{l}0.15268 \\
0.16225 \\
0.17420 \\
0.18969\end{array}$ & $\begin{array}{l}0.15428 \\
0.16378 \\
0.17557 \\
0.19073\end{array}$ \\
\hline 2.0 & 1.5 & $\begin{array}{c}0.0 \\
0.05 \\
0.1 \\
0.2\end{array}$ & 2.5 & 2.0 & 1.1 & $\begin{array}{l}0.12856 \\
0.15268 \\
0.18064 \\
0.25325\end{array}$ & $\begin{array}{l}0.12856 \\
0.15428 \\
0.18445 \\
0.26442\end{array}$ \\
\hline 2.0 & 1.5 & 0.05 & $\begin{array}{l}2.0 \\
2.2 \\
2.3 \\
2.5\end{array}$ & 2.0 & 1.1 & $\begin{array}{l}0.22240 \\
0.18667 \\
0.17347 \\
0.15268\end{array}$ & $\begin{array}{l}0.22423 \\
0.18844 \\
0.17518 \\
0.15428\end{array}$ \\
\hline 2.0 & 1.5 & 0.05 & 2.5 & $\begin{array}{l}1.0 \\
2.0 \\
2.5 \\
3.0\end{array}$ & 1.1 & $\begin{array}{l}0.23072 \\
0.15268 \\
0.13823 \\
0.12882\end{array}$ & $\begin{array}{l}0.23268 \\
0.15428 \\
0.13972 \\
0.13023\end{array}$ \\
\hline 2.0 & 1.5 & 0.05 & 2.5 & 2.0 & $\begin{array}{l}0.8 \\
0.9 \\
1.1 \\
1.2\end{array}$ & $\begin{array}{l}0.14422 \\
0.14685 \\
0.15268 \\
0.15593\end{array}$ & $\begin{array}{l}0.14566 \\
0.14834 \\
0.15428 \\
0.15759\end{array}$ \\
\hline
\end{tabular}




\section{FIGURES}

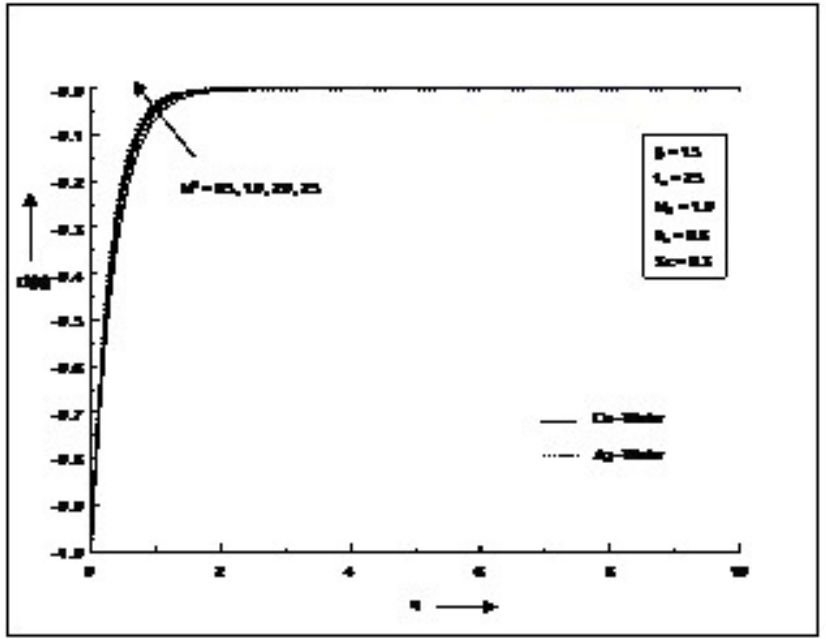

Fig.2 Velocity profiles for various values of $\mathrm{M}^{2}$

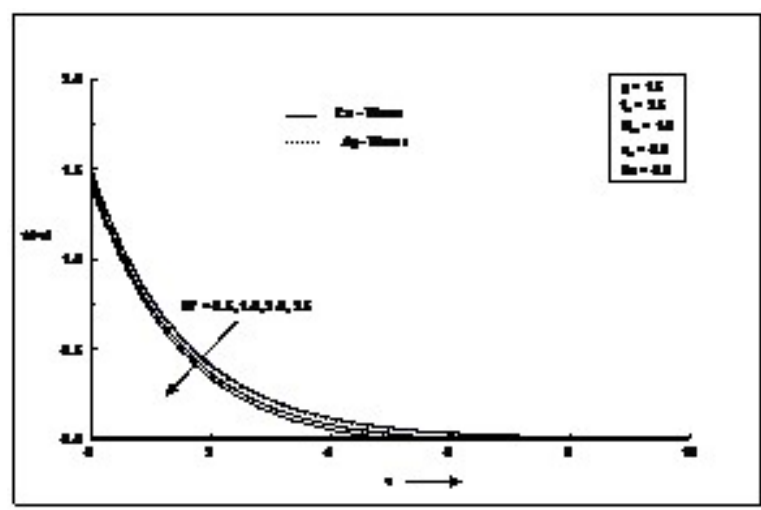

Fig. 4 concentration profiles for various values of $\mathrm{M}^{2}$

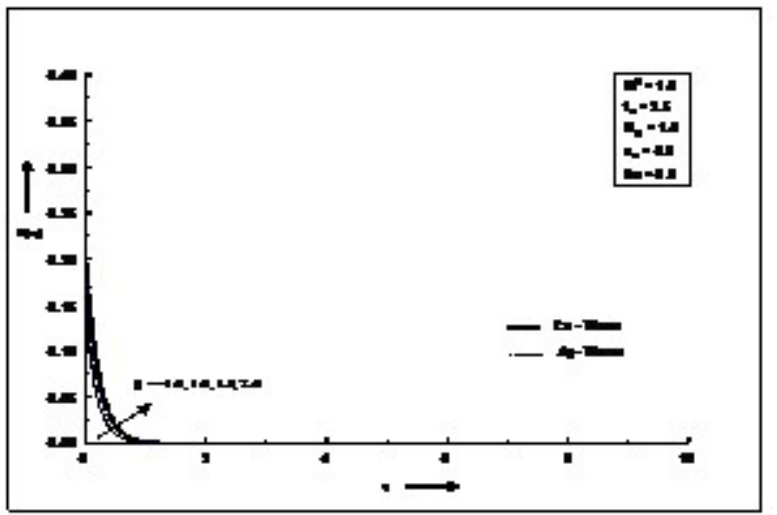

Fig.6 Temperature profiles for various values of $\beta$

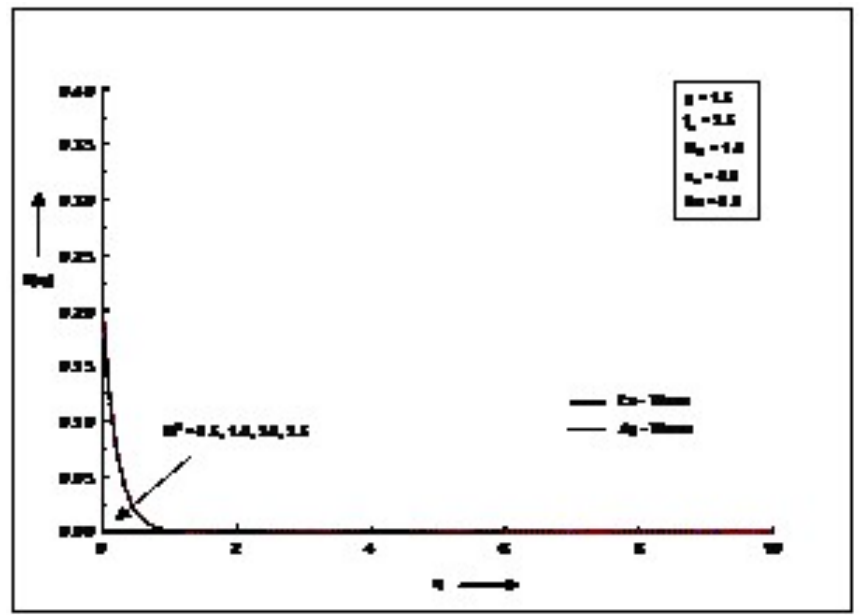

Fig.3 Temperature profile for various values of $\mathrm{M}^{2}$

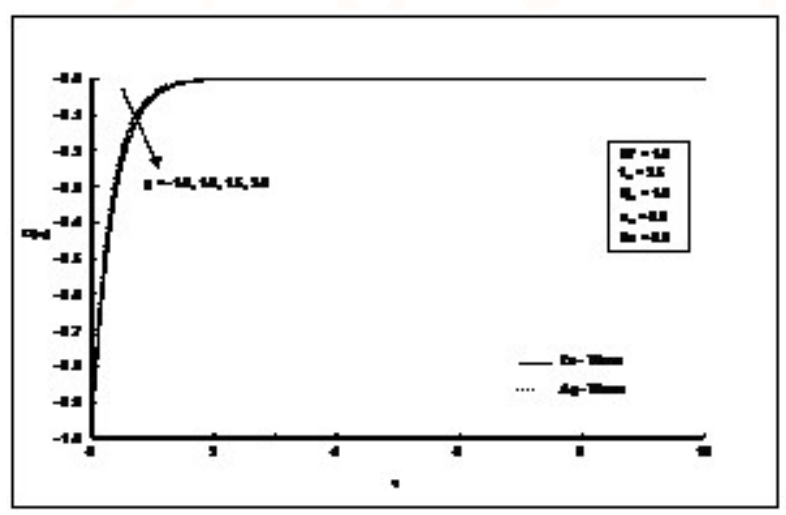

Fig.5 Velocity profiles for various values of $\beta$

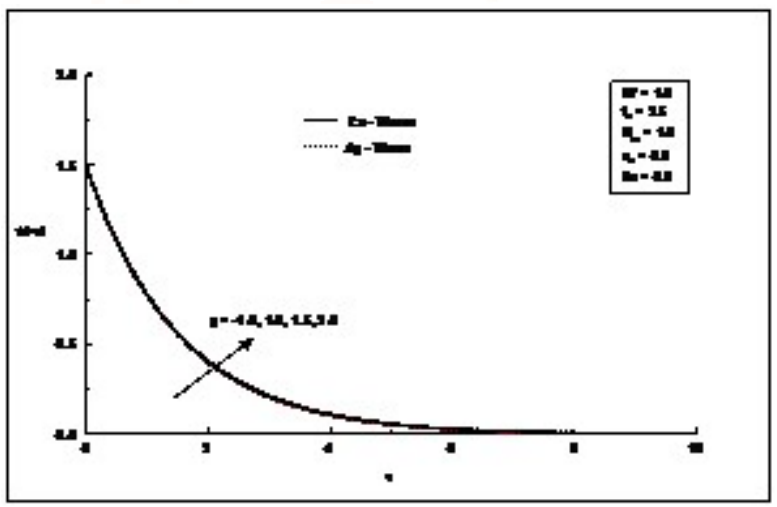

Fig.7 Concentration profiles for various values of $\beta$ 


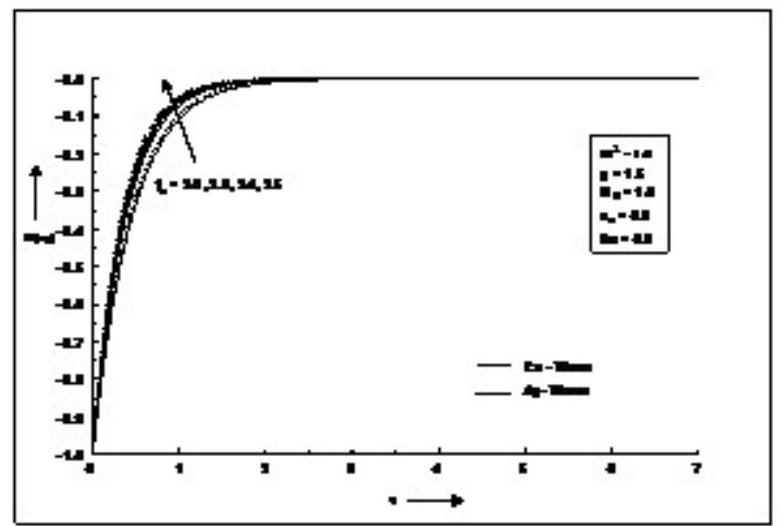

Fig. 8 Velocity profiles for various values of $\mathrm{f}_{\mathrm{w}}$

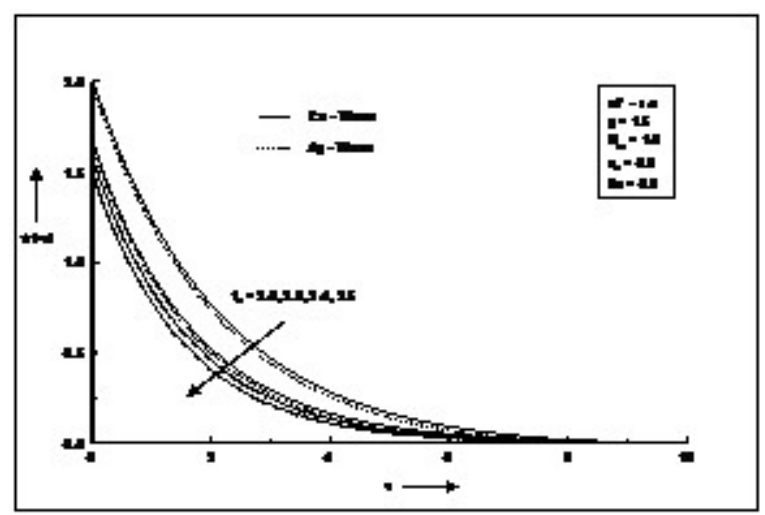

Fig.10 Concentration profiles for various values of $f_{w}$

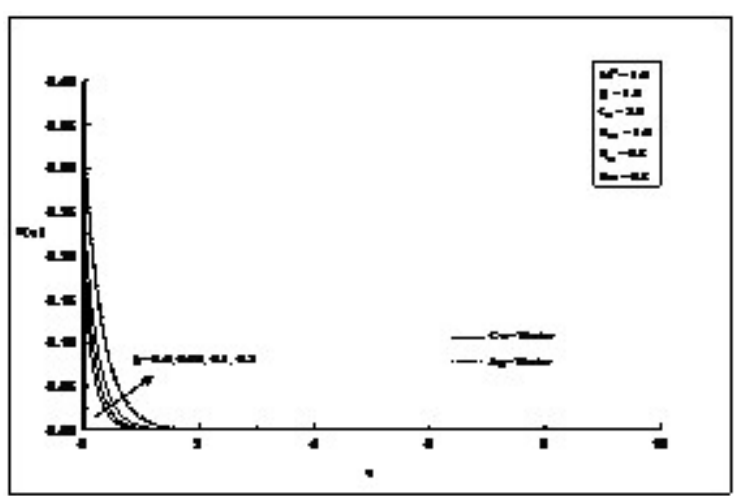

Fig.12 Temperature profiles for various values of $\phi$

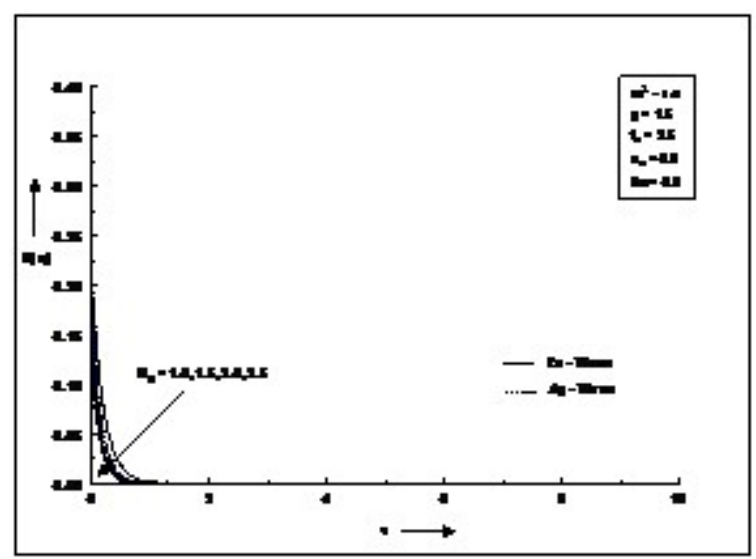

Fig.14 Temperature profiles for various values of $N_{R}$

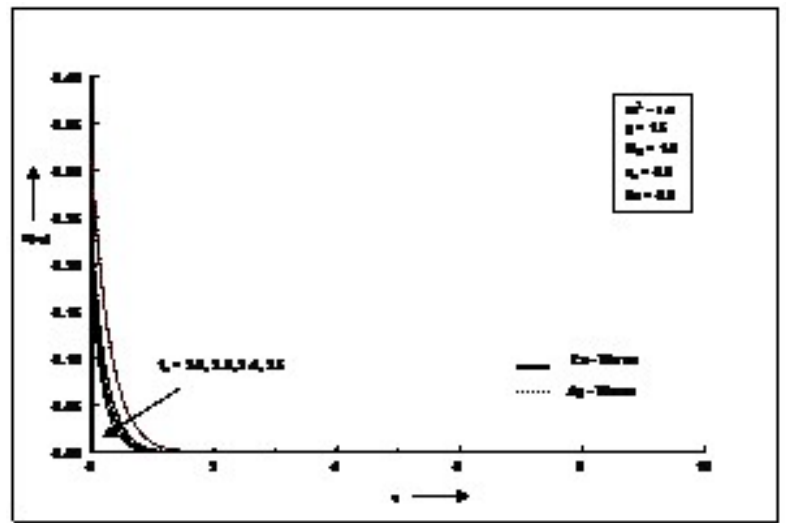

Fig.9 Temperature profiles for various values of $f_{w}$

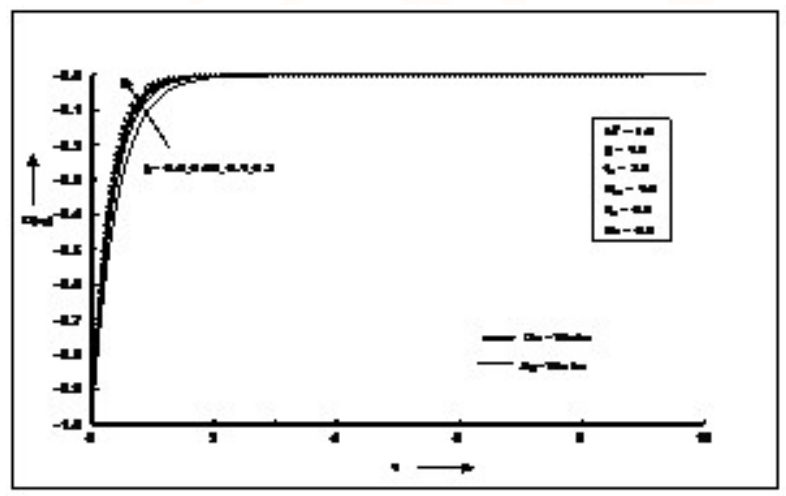

Fig.11 Velocity profiles for various values of $\phi$

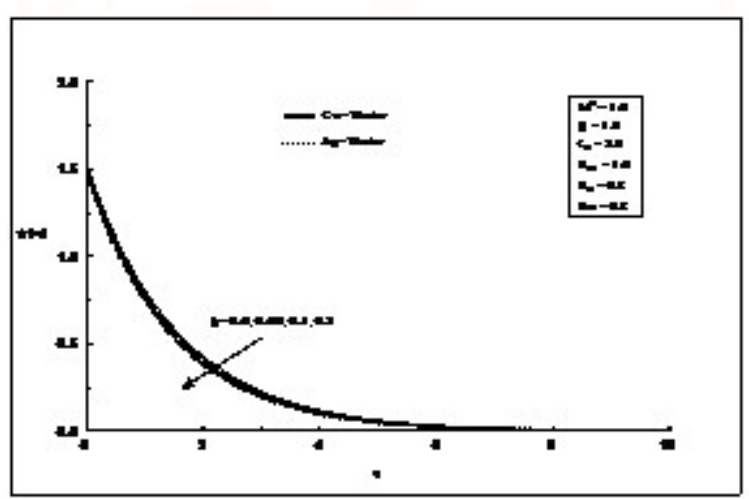

Fig.13 Concentration profiles for various values of $\phi$

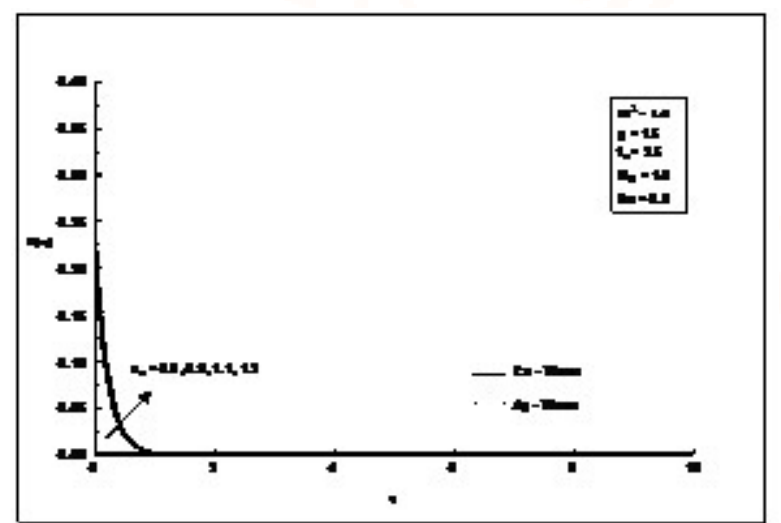

Fig.15 Temperature profiles for various values of $\theta_{\mathrm{w}}$ 


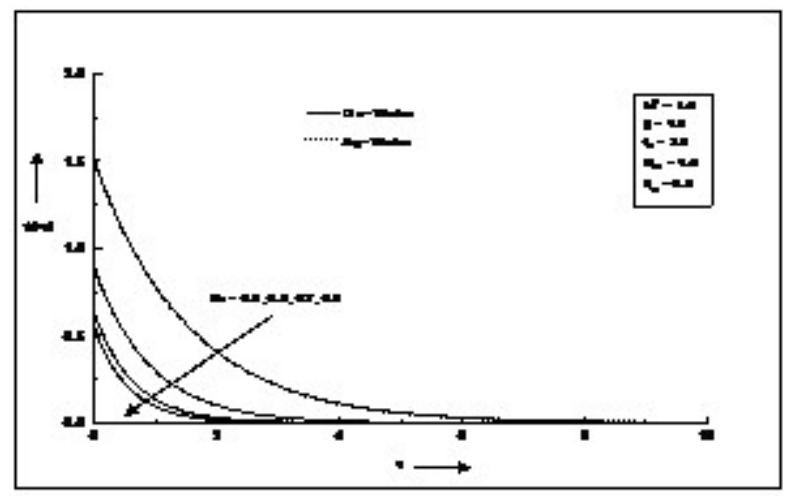

Fig. 16 Concentration profiles for various values of Sc

\section{REFERENCES}

1) Wang C.,Y., Liquid film on an unsteady stretching sheet, Quart. Appl. Math., 48,601-610(1990).

2) Miklav,M., and Wang,C.,Y., Viscous flow due to a shrinking sheet, Quarterly of Applied Mathematics, 64(2),283-290(2006).

3) Wang, C.,Y., Stagnation flow towards a shrinking sheet, International Journal of Non-Linear Mechanics,43(5), 377-382(2008).

4) Fang,T.,G., Zhang,J., and Yao,S.,S., Viscous flow over an unsteady shrinking sheet with mass transfer, Chinese PhysicsLetters,26(1),(2009).

5) Arifin,N.,M.,D., Nazar,R., Pop,I., Viscous flow due to a permeable stretching/shrinking sheet in a nanofluid, Sains Malaysia, 40, 1359-1367(2011).

6) Rohni,M., Ahmad,S., and Pop,I.,Flow and heat transfer over an unsteady shrinking sheet with suction in nanofluids, International Journal of Heat and Mass Transfer, 55(7),1888-1895(2012).

7) Bachok,N., Ishak,A. and Pop,I., Unsteady boundary-layer flow and heat transfer of a nanofluid over a permeable stretching/shrinking sheet, International J. of Heat Mass Transfer, 55,2102-2109(2012).

8) Mansur,S., AnnuarIshak, The flow and heat transfer of a nanofluid past a stretching/shrinking sheet with a convective boundary layer, Hindawi Publishing Corporation,(2013).

9) Kalidas Das, Nanofluid flow over a shrinking sheet with surface slip, Microfluidics and Nanofluidics, 16(1), 391-401 (2014).

10) Rahman,M., M., Teodor Grosan, Ioan Pop , Oblique stagnation-point flow of a nanofluid past a shrinking sheet, International Journal of
Numerical Methods for Heat \& Fluid Flow, 26(1),189 - 213(2016)

11) Andersson, H.,I., MHD flow of viscoelastic fluid past a stretching surface,ActaMechanica, 95, 227 230(1992).

12) Chaim,C., Hydromagnetic flow over a surface stretching with a power law velocity, International Journal of Engineering Science,33(3) ,429-435(1995).

13) Raptis, A., Massalas, C. V. , Magnetohydrodynamic flow past a plate by the presence of radiation,Heat and Mass Transfer, 1998, 34(2) , pp 107-109

14) Iswar Chandra Mandal and Swati Mukhopadhyay, Heat transfer analysis for fluid flow over an exponentially stretching porous sheet with surface heat flux in porous medium, Ain Shams Engineering Journal, 4, 103-110(2013).

15) Elbashbeshy, E.M.A., Radiation Effect on Heat Transfer over a Stretching Surface, Canadian Journal of Physics, 78, 1107-1112 (2000).

16) Maiti,A.,K., Effect of radiative heat flux of a magneto hydrodynamics micropolar fluid flow towards a stretching or shrinking vertical surface in presence of a heat source or sink, International Journal of Engineering Trends and Technology (IJETT), 9,389- 393 (2014).

17) Das,K.,Sarkar, A. ,Effect of melting on an MHD micropolar fluid flow toward a shrinking sheet with thermal radiation,Journal of Applied Mechanics and Technical Physics, 57(4), 681689 (2016).

18) Choi.S., Enhancing thermal conductivity of fluids with nanoparticles. In :Sidiner, D.A., Wang,H.P., (eds) Developments and applications of nonNewtonian flows, ASMEFED,231/MD, 99-105 (1995).

19) YiminXuan and Qiang Li, Heat transfer enhancement of nanofluids,International Journal of Heat and Fluid Flow, 21(1), 58-64 (2000).

20) Das, S.K., Putra, N., Thiesen, P. \&Roetzel,W., Temperature dependence of thermal conductivity enhancement for nanofluids. J. Heat Tr., 125, 567574,( 2003).

21) Phelan,P.,E., Bhattacharya, P. \&Prasher, R.S. Nanofluids for heat transfer applications. Annu. Rev. Heat Transfer, 14, 255-275(2005). 
22) Ding, Y., Chen,H., Wang,L., Heat transfer intensification using nanofluids, Kona, 25, 23-28, (2007).

23) Manca,O., Jaluria,Y., and Poulikakos,D., Heat transfer in nanofluids, Advances in Mechanical Engineering, 2010, 1-2 (2010).

24) Sualia,M., NikLonga,N.,M.,A.,, and Ishak,A., Unsteady stagnation point flow and heat transfer over a stretching/shrinking sheet with prescribed surface heat flux, App. Math. and Comp. Intel., 1,1-11(2012).

25) Winifred NdukuMutuku,MHD non-linear boundary layer flow and heat transfer of nanofluids past a permeable moving flat surface with thermal radiation and viscous dissipation, Universal Journal of Fluid Mechanics 2,55-68 (2014).

26) Eshetu and Shankar, B.,A steady mhd boundarylayer flow of water-based nanofluids over a moving permeable flat plate,International Journal of Mathematical Research,4(1),27-41 (2015).
27) SandeepNaramgari, Sulochana, C., MHD flow over a permeable stretching/shrinking sheet of a nanofluid with suction/injection, Alexandria Engineering Journal ,55, 819-827 (2016).

28) Fekry M Hady,Fouad S Ibrahim,Sahar M AbdelGaied and Mohamed R Eid, Radiation effect on viscous flow of a nanofluid and heat transfer over a nonlinearly stretching sheet,Nanoscale Research Letters, 1-13(2012).

29) Ishak,A., Nazar,R., Pop,I., Heat transfer over an unsteady stretching surface with prescribed heat flux, Canadian Journal of Physics , 86, 853-855 (2008).

30) Elsayed, M.,A.,Elbashbeshy, Daila A., Aldawody, Heat transfer over an unsteady stretching surface with variable heat flux in the presence of a heat source or sink, Computers and mathematics with applications, 60,2806-2811 (2010). 